Copyright (C) 2021 The Author/s

This work is licensed under a CC-BY 3.0 License

Peer review method: Double-Blind

Accepted: June 06, 2021

Published: June 18, 2021

Original scientific article

DOI: https://www.doi.org/10.47305/JLIA21720011v

\title{
GLOBAL HEALTH GOVERNANCE POST-COVID-19: TIME FOR A HIERARCHICAL ORDER?
}

\author{
Jean Vilbert \\ University of Wisconsin, Madison - Wisconsin, USA \\ ORCID iD: https://orcid.org/0000-0003-0223-2211 \\ jvilbertpere@wisc.edu
}

\begin{abstract}
The COVID-19 has renovated the debate about global health governance. Many scholars have proposed that the World Health Organization (WHO) should assume the position of a central coordinator with hierarchical powers. This article presents four main objections to this project: the problems with 'one-size-fits-all' policies, the heterogeneous distribution of power within multilateral institutions, the risks of crowding out parallel initiatives, and the democratic principle. Testing the WHO's ability as a provider of technical information, an OLS regression, analyzing the first year of the coronavirus health crisis, from January 2020 to January 2021, in 37 countries reported in the World Values Survey Wave 7, shows a negative relationship between the population trust in the WHO and the number of cases of COVID-19. This indicates that there is a valid case for countries to strengthen the WHO's mandate, but not to create a hierarchical global health structure.
\end{abstract}

Keywords: Global Health Governance; World Health Organization; COVID-19; Hierarchy; Sovereignty

\section{INTRODUCTION}

On 30 January 2020, the World Health Organization (WHO) declared the novel coronavirus an 'emergency of international concern' and on 11 March, elevated it to a pandemic. One year passed, as of 6 June 2021, 172.6 million cases and 3.72 million deaths caused by the COVID-19 have been reported worldwide (WHO 2021). For many scholars and scientists who have been studying the topic, the world's inability to prevent the spread of the disease did not come as a surprise. Moon and others, in an article published in 2017, pointed out that the world remained "grossly underprepared for outbreaks of infectious disease". According to their analysis, previous epidemics had shown that the global system for preventing, detecting, and responding to outbreaks was not reliable. The point may be that these earlier epidemics - Ebola, Zika, and yellow fever - were 'issues of concern to developing countries and maybe because of this fact did not drive great impetus to reforms in the global health system. The COVID-19, having hit hard the most powerful nations in the world, might be different. It may 
trigger what political theorists call an 'opportunity window' - a rare opening to push solutions and produce major changes in the status quo (Kingdon 2011). In this case, the willingness to change directs towards a more comprehensive model of global governance.

Authors like Tanisha Fazal emphasize that when the novel coronavirus abated over the Western, countries turned to the WHO but did so overestimating the organization's role and capacity (Fazal 2020). In Moon's words, some seemed to think the WHO had leverage over the Chinese Government and could even conduct independent investigations within its territory to get information about the disease. However, the organization has no legal or political power to do so. Put differently, some seemed to believe that the world had at hand a hierarchical entity with wide powers to address health emergencies when all is available is 'a loose, flat network', a web of independent actors negotiating horizontally the norms that regulate their interactions.

This fragmented picture is a striking feature of the current global health governance. In this system, the WHO is not properly a directive coordinator, but one of the actors in an archipelago of players. Such 'unstructured plurality' leads Barry Bloom, dean of Harvard University's School of Public Health, to argue that "there's no architecture of global health" (Cohen 2006). Fidler (2007) prefers a metaphor that compares this structure to open-source software, which "becomes a public good produced and applied by a broad spectrum of people and institutions with diverse interests that improves the more it is used". As such, global health governance does not flow from organized and centrally implemented authority but from open-source anarchy in which governments and non-state actors operate.

In any case, now that the world may better understand the WHO's role in the global order, there has been a strong push for a more consolidated architecture; one that allows for coordinated global health governance to confront challenges like the COVID-19 pandemic. As posed by Gostin (2020a), the question then is what does it mean to strengthen global governance? For him, it means that States will have to "share their sovereignty" to craft a more robust global system, which keeps partially the multipolar architecture, but tailors a position of commandment for the WHO, solidifying its global mandate with powers to ensure greater compliance at the national level, and political backing to stand up to governments that defy its directives.

Nevertheless, there are grounds for concern about this process of hierarchization in global health governance. This article addresses these issues by introducing conditions under which countries may justifiably limit the influx of international policies in the health area. It also addresses political questions that can undermine the WHO legitimacy and shows why a departure from the current horizontally open architecture might not produce the best outcomes. There is a valid case for the WHO's operations to be strengthened post-COVID-19 but through knowledge and resource provision, not hierarchical coordination. In the following items, 
this study will present a range of reasons why countries, in particular the developing ones, should eschew the temptation to create a hierarchical global health structure, which may not only fall short due to countries' asymmetries but is likely to create losers in the process.

\section{CAVEATS FOR A WHO'S ENLARGED MANDATE}

Global governance, as discerns Patrick (2014), is a "slippery term". If in the past it denoted a world government, today it refers to a more concrete idea: the network made up by governments, international organizations, and other non-state actors to address challenges that transcend national borders. This web has sharply expanded in recent years, coining multilateral bodies that are far more intrusive than the conventional international project (Zürn 2012). Yet, in the face of themes such as global warming, nuclear proliferation, money laundering, and pandemics, whose effects are indistinctly spread around the globe and resistant to the control of even the most powerful governments, many scholars believe that there is no transnational workable mechanism able to implement proper measures to ensure efficient outcomes (Nordhaus 2005). The novel coronavirus crises may underpin this conclusion. As Frenk and Moon (2013) argue, an arrangement robust enough to respond to the challenges posed by the agenda of repetitive infections and reproductive health problems demands reinforced health structures not only at the national but at the worldwide level - this is the rationale for a global health system.

Still, there are at least four major issues that need to be addressed before moving to a model of global health governance that entails, in practical terms, a more centralized and hierarchized management, namely: (1) The potential ineffectiveness of universalized policies when applied to places with a distinct set of characteristics without the necessary adjustments; (2) Legitimacy questions regarding geopolitical stances and the balance of power that surrounds multilateral institutions; (3) The possible crowdingout of parallel initiatives due to the hierarchization of the system; (4) Questions related to health often go beyond the WHO's scope, some of which may demand specific submission to the democratic principle, domestically.

\section{Universal Policies: One Size Does Not Fit All}

Since the beginning of the pandemic, the WHO has recommended that governments adopt strict rules of social distancing and reduced individual mobility (WHO 2021). Such measures are costly and sometimes of questionable efficacy, but whenever governments fail to curb the disease through early contact tracing, they are left with few options but to concede to them (Vicenti 2020). In this context, like Paul, Brown, and Ridde (2020) observe, following the WHO recommendations, and under 
internal and international pressure, some governors have adopted a set of one-size-fitsall policies without performing their adapted risk assessment, which can be problematic. Far from downplaying the severity of the health crisis, but it makes little sense to transfer procedures applied for a country where the median age is forty-five to a country with a median age of twenty-five, given the mortality rate of COVID-19 is more than sixty times higher among those ages sixty-five or older (Yanez 2020). Before incorporating a 'copy and paste' mechanism, countries should consider their characteristics as nations, which may substantially affect the efficiency of 'imported' policies.

Peru is an illustrative example of how the lack of adjustment can lead universal policies to fail due to contextual determinants. In a piece in the New York Times, Taj and Kurmanaev (2020) affirmed that "President Martín Vizcarra followed the best advice when the coronavirus arrived in Peru". By that, they mean that he ordered one of Latin America's first and strictest lockdowns. "Yet instead of being lauded as a model of disease control, Peru has become one of the world's worst coronavirus hot spots" when the article was written, in June of 2020, Peru had 219 new daily cases per million of population, the fourth biggest outbreak in the world (Roser 2021); currently the performance of the country is considered by the Lowi Institute the worst among 102 countries analyzed (Leng and Lemahieu 2021). Then the very article gives the possible reasons for the failure: Peruvians were asked to wash their hands and stay at home, but only one-third of the poor households have running water, they have little to no savings and, even though they were given some money, only half of the homes have a refrigerator, which forces families to return day-to-day to crowded markets, a major source of infection. The conclusion must be that whether the related social factors were not considered in the design and implementation of the policy, actually President Vizcarra did not receive, nor did he follow 'the best advice'.

In situations of strong common interest and need for high levels of social (international) cooperation, like a pandemic, the much necessary coordination comprehensively makes centralized command-and-control instruments much more attractive. However, this should not obscure the political common sense that the decision-making at the local level is normally more effective (Muller 2018) and that 'one-size-fits-all' policies usually fail (Mehtar 2020). The reason for that is straightforward: each society must adjust solutions to its particularities. For instance, cultures considered 'tight' (with strong norms), such as Singapore, Japan, and China may have more means to enforce sanitary measures than 'loose' cultures (with higher tolerance of deviant behavior), such as those of the United States, Italy, and Brazil (Gelfand, Harrington, and Jackson 2017). Moreover, North American and much of Western European cultures tend to positively value acts like kissing and hugging, a factor of interpersonal transmission of the virus, which is much less common in Asian cultures. Policies to be applied to these countries cannot be the same. 
To counter-argue, one could say that strengthening the WHO's mandate does not mean that health policies will unavoidably become 'from top to bottom' or inflexible. However, historical experience shows that when international organizations have sufficient leverage to impose their 'ideal' solutions, they do so. The International Monetary Fund (IMF) is a vivid example of this: whether called to offer technical advice and financial assistance to liquidity crises, the IMF has used the opportunity to impose broad economic reforms, whose fit was at times highly controversial - in the 1990s, acting in Southeast Asia, the Fund tried to follow much of the same guidelines applied before in Latin America, Eastern Europe, and the former Soviet Union, even though the situation of the Asian countries was drastically different (Feldstein 1998). Nothing guarantees that the WHO will not follow the same path.

\section{Legitimacy: The WHO Is Not a Political Island}

The same theories of power and principal-agent theory that constraint international organizations to follow the commands of powerful states (Bauer 2007) apply to the WHO, which cannot be insulated from its political context. International organizations are rarely if ever neutral, but part of a complex web of qualified interests. Therefore, the risks associated with the WHO falling under the influence of member states will be potentialized in a hierarchical structure. This is aggravated by the existence of governments that do not share values like transparency and respect for individual rights (Raustiala 2016).

Regarding this last aspect, it is worth remembering that the WHO received great criticism, especially but not exclusively from the United States, for its early handling of the COVID-19 crisis, when it was accused to let itself be manipulated by the Chinese government, having understated the seriousness of the diseased, conveyed misinformation provided by Chinese authorities, and praised China for its response to the outbreak (Fazal 2020) - the suspicion that an organization may be acting as a spokesperson for a country or, worse, as a venue for some governments to influence and control policies adopted in other nations is a critical aspect to undermine the organization's legitimacy in the international order.

Finally, the somehow old-fashioned division North-South is also an issue here, once developed countries still retain a great deal of control over the agenda and interior bureaucracy of the WHO (Chorev 2012). In this sense, even though most non-state actors are from the Northern portion of the globe as well, the anarchy of competing agents at least provides relative open access and facilitates that conflicting interests make the apparatus difficult to be controlled by one single entity. Thus, the current model might be more democratic than a 'lord-commander' with a formal mandate to hold a strong grip over global health governance. 
There are many reasons to complain about the current global health system. Paul, Brown, and Ridde, for example, call for a shift from a reactional archetype to a preventive model that adopts a holistic approach to tackle upstream causes and determinants of diseases, helping populations to reduce risk factors and augment their natural immunity (Paul, Brown, and Ridde 2020). Moon and colleagues do not deny this reactionary mode, but add that, inconsistently, the system lacks an emergency culture that allows for quick decisions. The final result may be a system that is not robust enough to deal with the threats of the present and the future. Nonetheless, it is important to notice that the fragility of the system is partially related to current WHO's institutional problems, such as the vulnerability to the pressure of member states, minimal transparency, and little accountability after failure (Moon 2017) which are not simple problems to solve and might be intensified with the augment of powers and financial resources.

To make matters worse, elevating the WHO's position may crowd out parallel initiatives that today are relevant in ameliorating the system, especially those headed by non-state actors like the Rockefeller and the Gates Foundation (Andreoni and Payne 2003), the latter with investments that outspend many governments (Dieleman 2006). As Fidler alerts, "the Gates Foundation will no more march to the tune of WHO than the United States will to the cadence of the UN" (Fidler 2007).

Of course, the consequences of non-state actors' preferences in terms of global health still need to be better understood. According to some positions, this multistakeholder governance might be a Trojan horse for the foundations of multilateralism (Sridhar and Woods, 2013), a strategy adopted by powerful states to neutralize the numerical advantage that developing nations have in the WHO, creating a plethora of organizations over which they exercise easier dominance (Moon forthcoming). As a counterargument, part of the informational role the WHO can exercise (a topic that will be further developed ahead) involves tapping into 'pet projects' of non-state actors and report which interest they are serving, such that countries and the international community can decide if they make sense in the context of a sound strategy for global health.

\section{Risks to the Democratic Principle}

According to a critic scholarship, globalization not only restrains the states' autonomy but also disables democracy by inflicting the convergence of national policies. Thus, the structural change in the very nature of sovereignty is an expected consequence of the transformation of the fundamental structures of international politics, from an anarchic architecture to a global governance system (Zürn 2012). 
Put differently, in domestic politics, governance is straightforward, once exercised by a government vested with formal authority to define and enforce binding rules. The international domain, conversely, is composed of independent sovereign entities that recognize no superior authority (Patrick 2014). Global governance brings ambiguity to this dichotomy. Specifically, in the present case, the tension between international order and domestic democracies arises because the consequences of health policies can be enduring and countries might have to deal with the side-effects of measures imposed by multilateral organizations. For example, the WHO does have a scientific basis to advise for lockdowns - which it would secure more energetically if had the powers thereof - once researchers have affirmed that "only strict quarantine measures can curb the coronavirus disease" (Sjödin et al. 2020). However, countries individually must assess adverse effects (Wang 2020), such as depression, anxiety, stress, and even suicides (Sher 2020), according to the underlying conditions of their populations. Also, at some point, if the lockdowns are not strictly necessary, nations should be able to opt for less extreme measures to avoid the general deterioration in population mental health (Pierce et al. 2020) - as a social species, humans are negatively affected by isolation and loneliness, hypervigilance, and feelings of vulnerability, which are associated with increased morbidity and mortality (Hawkley and Cacioppo 2010), effects that may last long after the pandemic and the lockdowns have passed. This argument now may seem unreasonable, considering the extensive academic support for strong mitigating measures against the COVID-19, a disease that has spread across the entire globe. The evaluation could be quite different if the spread of the disease was limited to developing countries and the WHO was setting tough measures, with extraordinary socioeconomic impacts, to contain the virus and prevent it to hit other (developed) nations. Granting to the WHO the power to fight pandemics with the necessary measures to be effective can have several unintended effects plus some that are foreseeable - it would relativize national democracies, especially in countries with reduced international leverage (mostly in the global South), in extreme cases deactivating the right of peoples to make their own choices about serious and controversial matters. Lastly, countries have other interests to balance beyond the WHO's scope, even during a health crisis. From an economic and political perspective, for instance, responding successfully to a pandemic has to mean complementary things that involve not only direct impacts (reducing the spread of the virus and the number of deaths) but also dealing with social and economic consequences (Roser 2021). Illustratively, a response that brings increasing rates of poverty and higher mortality from other causes, often associated with economic determinants (Cockerham, Hamby and Oates 2017), disproportionally affecting the poorer (Fothergill and Peek 2004), cannot be considered successful. All these further problems are not part of the WHO sphere and may not be assessed properly in the design provided by well-intentioned 'ideal' international policies. 


\section{WHAT IS THE WAY FORWARD?}

If a hierarchical global health system presents unintended consequences and predicted risks, unilateralism is far from being the solution. It is hard to imagine that a country, acting alone, would be able to respond effectively to health threats like the COVID-19 in a globalized world. While island states like New Zealand and Cuba can control their borders with increased efficacy, most countries are not islands to secure mitigation successes through isolationism (Fazal 2020). Additionally, misrepresenting caution in terms of embracing policies drawn abroad with unreceptiveness or unjustified skepticism can have disastrous outcomes.

Brazil may be included in this last reactionary category: if the Peruvian authorities rushed to emulate policies applied abroad with little or no adjustment, the Brazilian federal government refused any advice from the international community. (Watson 2020) The administration has never adopted explicitly the Sweden light-touch style (McLaughlin 2020), but also did not embrace the WHO's guidance (Ferigato et al. 2020). Under the federal government's erratic behavior, subnational powers had to undertake most measures against the pandemic. However, the lack of coordination in implementing coherent policies may partially explain why the country became the world's worst COVID-19 hot spot as of March 2021 (Roser 2020). A report from the University of Oxford showed that by June 2020, testing in Brazil was infrequent, and staying at home for a full fortnight was exceptional, in both cases even among potentially infected people. And although the WHO's recommendations were not being met, at that time many subnational governments were already starting to relax social distancing rules (Petherick et al. 2020).

The contradiction arising from the comparison between the opposite actions of the Peruvian and Brazilian governments, which led both countries to similar calamitous outcomes - (Brazil with 59.2 thousand cases per million people and Peru with 46.5 thousand as of March 30, 2021) (Roser 2021) - may be the key to solve this riddle. The COVID-19 crisis has cast light on the necessary equilibrium between international and domestic orders. States, then, are called to work on this symmetry and build a governance landscape that recognizes health as a global issue (Gostin 2020b) but that strengths systems at the local level, such that nations can tailor the best policies, according to their specificities, to answer to their populations' choices and needs (Paul, Brown and Ridde 2020).

It is fair to say that a more robust hierarchized system could potentially offer enhanced standards for preventing, detecting, and responding to infectious disease outbreaks - it has a higher ceiling under perfect conditions. Yet, conditions are never perfect and, besides the grounded skepticism on the efficacy of 'universal' solutions for problems embedded in local circumstances; other values are at stake, including the right of peoples to self-determination, democracy, and equity. As an illustration, the Institute 
Lowy classified political systems as democratic and authoritarian and found that on average the latter performed better at containing the spread of COVID-19 (Leng and Lemahieu 2021) - it is assumed that few academics would support increasing authoritarianism to reach effectiveness at managing health crises. At the same time, it might be easy for developed states to promote a hierarchical global order knowing they will be able to make the most of it - the dangers for their sovereignty and ambitions are significantly smaller. However, developing countries are unlikely to receive the same package of costs and benefits.

Drawing these elements together, nation-states should not 'share their sovereignty' with the WHO. Governments have a responsibility to be a cushion between international policies and the domestic order. In Zürn's (2012) reflection, "higher levels of economic openness increase the demand for policies to buffer the less desirable effects of world market integration". Similarly, higher levels of multilateralism demand national governments to filter the less desirable effects of international integration. This conclusion applies to a wide range of situations, from foreign aid and investment (with possible imperialist hidden purposes) to health-driven intervention and crisis management.

Thus, if the question for the future, as Moon and others perceive, is whether the WHO will be mandated and if states will bestow it with greater hierarchical authority, we hope the answer is, at least in part, negative. Despite the criticism on the fact that the WHO's main function today is not as a directing authority, but as an advisor (Moon forthcoming), it is possible to adopt a more positive interpretation of this conjuncture and advocate exactly for the strengthening of the knowledge-based function. As a fruit of specialization, the WHO possesses singular expertise to provide decisive consultancy and support (Hawkley and Cacioppo 2010) in the health area, whose beneficial effects should not be underestimated.

Borrowing the concepts and interpretation by Ravallion, a knowledge institution can serve as a broker that recruits existing knowledge and conveys it to the needy recipients. It can also identify pressing knowledge gaps and sensitive areas of ignorance, then producing information to address such flaws. It might seem too little, but the information in the context of global health, besides its direct effects and positive externalities, can help solve coordination failures stemming from complementarities in the decisions and actions of nation-states. A well-functioning global institution, which can be the WHO, properly structured to solve deficiencies arising from decentralized and fragmented sources of information, can generate economies of scale in knowledge development and reduce free-rider problems. This context is auspicious to produce efficient coordination and incites broader cooperation (Ravallion 2016).

Understandably, the current model may sometimes be seen as miscellanea, but as Boettke (2021) emphasizes, the difference between bureaucratic and democratic administrations is that democracy pushes the decision increasingly down to overlapping 
competing jurisdictions, while bureaucracy relies mostly on experts immune from people's engagement. Democratic models are by nature messy but responsive to the citizenry. Bureaucracy administration is technical, but when the monopolist expert makes an error, there is no mechanism for correction because the decision is from top to bottom. And this is not a rebellion against experts. They are critically important to the problem-solving process, insofar as within a democratic framework, in which people can govern themselves guided by the information they provide. This system does not require submission and outsourcing of the decision-making; it informs and qualifies the process.

Against this background, a way forward is to center the WHO's mandate in developing worldwide mechanisms to make information available and accountability possible, by generating and spreading trustworthy knowledge at the global, country, and regional levels. In this framework, analytical tools and other simple measures could promptly enhance the system, such as: (a) an integrated platform for exchanging epidemiological data between governments (Moon 2017); (b) investment in easing data collection and transparency, making public the main threats countries face and pose; (c) an accredited index of pathogeneses and other risk factors; (d) a catalog of specificities of the populations' habits and immunity, as well as relevant constraints to plans of action. These and other complementary initiatives (e.g. financial mechanisms to incentivize countries to report outbreaks rapidly and political instruments within the United Nations to hold them accountable in case of delay) would allow for a more holistic and preventive approach, which, aligned with technical support and the supply of public goods across borders, will result in better coordination and cooperation, with political costs and risks infinitely lower than a radical hierarchization of the global system.

Are these improvements enough to deal with threats of the magnitude of the novel coronavirus? Critics of the current system will probably say they are far from sufficient to equip the WHO for such challenges. Indeed, foreseeing the future is always a controversial business. In any case, a straightforward way to estimate what might happen tomorrow is to look at what happened yesterday. In the last part of this piece, a statistical analysis evaluates how, on average, performed countries during the first year of the COVID-19 pandemic, according to the levels of trust in the WHO, with which it is possible to discuss the WHO's role as a provider of dependable, but not binding, information. 


\section{TESTING THE ARGUMENT}

If the WHO can play a significant role as a provider of relevant information, and this is enough to make an impact in the response against the virus, then countries where the levels of trust in the WHO are high should typically perform better. To test this hypothesis, we estimate the association between the number of cases of COVID-19 (per million people) and the reported popular trust in the WHO in 37 countries - the nations that had information about this parameter ${ }^{1}$ in the World Values Survey Wave 7 (20172020) (Haerpfer et al. 2020). All data that has no other source specifically assigned was collected from 'Our World in Data' (Roser 2021). The number of cases per country considered the period from the beginning of the pandemic up to January 12, 2021 before the start of the vaccinations, which is one more criterion (a decisive one) to differentiate countries and lead to complex results.

There is no metric to directly state the level of information a country received from the WHO and how it was relevant to drive decisions in the context of the COVID19 pandemic. To overcome this hurdle, this piece assumes that the popular trust in the WHO can serve as a proxy for the level of the organization's proximity and how its recommendations are circulating in a country. On average, countries where the population presents higher levels of trust in the WHO will be the ones where the organization has greater penetration and conceivable influence. Conversely, to say that policymakers will follow the WHO's guidance in such cases would be an extrapolation, which makes the metric a suitable middle ground to test not the compliance with the WHO's policies, but the informational dimension. Therefore, aware of a series of variations over time and across countries that can impact individual cases, this method still allows for the inferences within the restrained scope of the study, once when individual countries are compared with the overall results, it is possible to assert that there is no distortion in the findings.

To prevent omitted factors, control variables were included after the first estimation. Model 2 inserts Human Development Index (HDI) and Gini to control for economic and socioeconomic variations across countries, which could lead states with similar policies to different results. Mode/ 3 includes the percent of the population aged 65 and above (Aged Pop) and population density (Pop Density), two parameters that are considered important to the effects and spread of the disease (Rocklöv and Sjödin 2020) and the number of cases effectively reported (Sjödin et al. 2020). Model 4 controls for government stringency, ${ }^{2}$ according to the Oxford COVID-19 Government Response

\footnotetext{
${ }^{1}$ Egypt, Hong Kong, Kazakhstan, Kyrgyzstan, Lebanon, Macau, Puerto Rico, and Taiwan were excluded due to the lack of data in the additional variables described ahead.

${ }^{2}$ The index sets value between 0 and 100 for each country, considering ten metrics: school closures, workplace closures, cancellation of public events, and restrictions on public gatherings, closures of public transport, stay-at-
} 
Tracker (Hale et al. 2021), and tests for coronavirus per thousand of population, such that differences between countries with high and low trust in the WHO can be seen even when compared with countries that adopted similar degrees of strictness. Finally, Model 5 adds trust in science (Science) and obedience to the rules (Compliance), ${ }^{3}$ to ensure that the coefficient on trust in the WHO is not overestimated by the absence of such elements of human capital.

The basic 'Ordinary Least Squares' (OLS) in the more complete step takes the following form, where the dependent variable Cases of COVID-19 is the outcome, $B_{i}$ indicates the coefficients for the constant and explanatory independent variable, $\pi_{i}$ stands for the overall control variables, $\gamma_{i}$ represent the two human capital control variables, and $\varepsilon$ is the standard error:

Cases COVID19

$$
\begin{aligned}
& =\beta_{0}+\beta_{1} \text { TrustWHO }_{i}+\pi_{1} \text { HDI }_{i}+\pi_{2} \text { Gini }_{i}+\pi_{3} \text { AgedPop }_{i} \\
& +\pi_{4} \text { PopDensity }_{i}+\pi_{5} \text { Stringency }_{i}+\pi_{6} \text { Tests }_{i} \\
& +\gamma_{1} \text { TrustScience }_{i}+\gamma_{2} \text { Compliance }_{i}+\varepsilon
\end{aligned}
$$

It needs to be stressed that the purpose of this analysis is not to estimate the effects of the WHO recommendations on the performance of countries that followed its guidelines, which would be in some degree contradictory with the argument that following the guidance without temperaments may lead to harmful outcomes. The underlying hypothesis is that shared resources plus timely, relevant and reliable information, once received and adjusted by each country to tailor its policies or incorporated by the population itself (to some degree, people can follow the WHO's guidance regardless of government actions), is a critical aspect in the answer to health emergencies and should spark higher levels of spontaneous coordination. As a result, better overall performance is expected in comparison to a context of fragmented or inexistent information and a lack of instrumented cooperation. It might be a strong assumption, but it is a reasonable one, which simplifies the analysis and avoids the endeavor to evaluate country by country - in each dimension of the proposed policies over time - something extremely complex and subject to multiple measurement errors.

home requirements, face covering, public information campaigns, restrictions on internal movements, and international travel control.

${ }^{3}$ Trust in Science: average answer per country when respondents were asked how much they agree with the statement that "Science and technology are making our lives healthier, easier, and more comfortable" - 1 meant "completely disagree" and 10 "completely agree" (Question 158); Obedience to the rules: mean answer per country when respondents were asked how essential it is, as a characteristic of democracy, that "people obey their rulers" - 1 meant "not at all an essential characteristic of democracy" and 10 meant it definitely is "an essential characteristic of democracy" (Question 248). Source: World Values Survey Wave 7 (2017-2020). 
Table 1 reports the correlations and robust standard errors of the regression of the dependent variable (Cases of COVID-19 per million people in a country) on the mentioned independent variables, by steps.

Table 1: Results of OLS Regressions

\begin{tabular}{|c|c|c|c|c|c|}
\hline & $(1)$ & (2) & (3) & (4) & (5) \\
\hline Trust WHO & $\begin{array}{c}-609.261^{* \star \star} \\
(119.306)\end{array}$ & $\begin{array}{l}-514.188^{\star \star \star} \\
(127.552)\end{array}$ & $\begin{array}{c}-499.154^{\star \star *} \\
(130.313)\end{array}$ & $\begin{array}{c}-416.305^{\star \star \star} \\
(113.174)\end{array}$ & $\begin{array}{c}-454.666^{\star \star \star} \\
(113.733)\end{array}$ \\
\hline $\mathrm{HDI}$ & & $\begin{array}{c}40565.679 \\
(20856.591)\end{array}$ & $\begin{array}{c}21732.210 \\
(36437.121)\end{array}$ & $\begin{array}{c}-1.24 e+04 \\
(28150.790)\end{array}$ & $\begin{array}{c}-2269.826 \\
(30181.750)\end{array}$ \\
\hline Gini & & $\begin{array}{c}461.788 \\
(301.720)\end{array}$ & $\begin{array}{c}501.259 \\
(282.398)\end{array}$ & $\begin{array}{c}576.932 \\
(306.605)\end{array}$ & $\begin{array}{c}912.781^{*} \\
(342.450)\end{array}$ \\
\hline Aged Pop & & & $\begin{array}{c}324.260 \\
(449.420)\end{array}$ & $\begin{array}{l}877.401^{*} \\
(401.721)\end{array}$ & $\begin{array}{l}929.673^{*} \\
(400.740)\end{array}$ \\
\hline Pop Density & & & $\begin{array}{l}-5.329 \\
(7.630)\end{array}$ & $\begin{array}{l}-4.710 \\
(4.230)\end{array}$ & $\begin{array}{l}-8.007 \\
(4.429)\end{array}$ \\
\hline Stringency & & & & $\begin{array}{l}524.842^{* *} \\
(145.697)\end{array}$ & $\begin{array}{l}561.233^{\star *} \\
(155.209)\end{array}$ \\
\hline Tests & & & & $\begin{array}{c}22.770 \\
(11.928)\end{array}$ & $\begin{array}{c}21.266 \\
(10.397)\end{array}$ \\
\hline Science & & & & & $\begin{array}{l}7694.414^{*} \\
(2830.062)\end{array}$ \\
\hline Compliance & & & & & $\begin{array}{c}-363.508 \\
(1980.095)\end{array}$ \\
\hline$N$ & 37 & 37 & 37 & 37 & 37 \\
\hline$R^{2}$ & 0.374 & 0.473 & 0.484 & 0.670 & 0.710 \\
\hline
\end{tabular}

Note: Robust standard errors in parentheses ${ }^{*} p<0.05,{ }^{* *} p<0.01,{ }^{* \star *} p<0.001$

In all models, trust in the WHO had a negative association with the number of cases of COVID-19. And despite the inclusion of the control variables - potential factors that could be hidden in the error term, in that case making the estimation biased - the coefficient kept its strength with statistical significance at any alpha level. Being a levellevel model, but considering that 'Trust $\mathrm{WHO}^{\prime}$ is reported in a percent scale, each percentage point increase in the trust in the WHO in a country was associated with a 
decrease, on average, of 455 cases of COVID-19 per million people, all else equal ( $\beta=-$ 454.666; Robust SE 113.7331; $\mathrm{P}=0.000 ; 95 \% \mathrm{Cl}=-688.0271,-221.3049 ; \mathrm{R}^{2}=0.7104 ; \mathrm{F}=$ 11.18). This negative correlation is depicted in Figure 1 , perhaps underpinning empirically the WHO's ability to develop and disseminate useful knowledge.

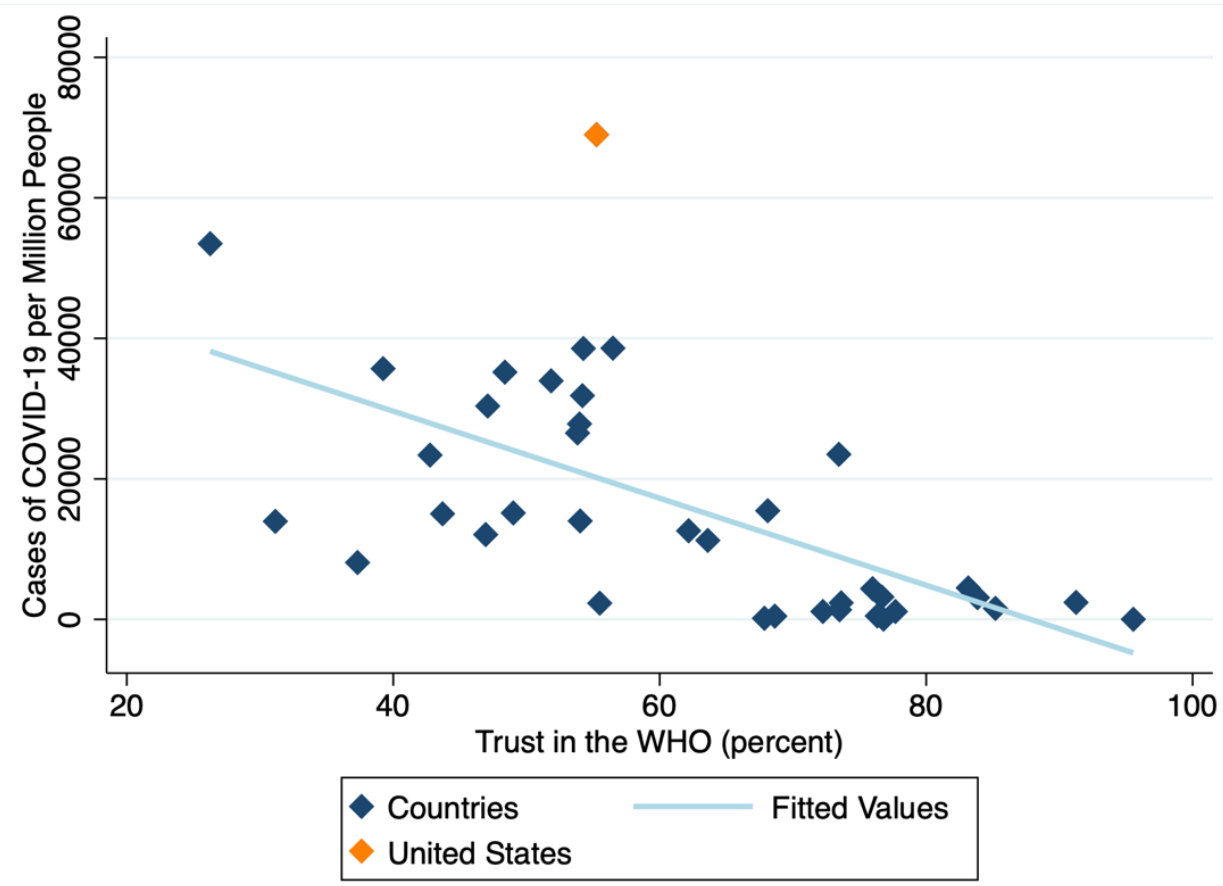

Figure 1: Trust in the WHO and Case of Coronavirus (Feb/2020 - Jan/2021)

An interesting aspect of the graph above is that the observation for the United States, the highlighted dot in the upper center of the graph, presents a high positive residual that is; the United States (US) performs much worse than the model predicted according to the popular level of trust in the WHO in the country. With no intention to assert causality, it is worth remembering that the Trump administration withdrew from the WHO amid the crisis (Gostin 2020b), which may help understand the background of this abnormal result - in terms of deviance from the prediction.

From a data analysis perspective, the regression seems to confirm that the popular trust in the WHO is a good proxy for countries' access to information and guidance - the US being an outlier - and suggests that countries that are likely to be more closely tied to the global health network (again, assumed by the higher level of popular trust in the $\mathrm{WHO}$ ) performed better in the first year of the pandemic, precisely when information was more critical due to the elevated degree of uncertainty regarding all the aspects of the pandemic. The R-squared value of 0.7104 reveals a good model fit. In other words, the independent variables explain 71.04 percent of the variation observed in the dependent variable - the number of cases of COVID-19. 
There is not a threshold that determines automatically when a regression is good enough, but data from observational studies, such as the present, might be taken as evidence of a useful regression when the R-squared is at least 30 percent (Veaux, Velleman and Bock 2020).

A question that arises is whether this finding is not persuasive to grant the WHO the authority it needs to exert a more directive role in global governance. For the WHO does not have the power to sanction states for reporting failures, China lagged to report SARS; Saudi Arabia to report MERS; Sierra Leone, Liberia, and Guinea were slow to report Ebola (Fazal 2020). Even though most nations benefit from it, the dynamics of open-source anarchy allow states and non-state actors to resist international rules and pose risks to the whole global community. In this train of thought, with more powers, the WHO could perform even better.

Numbers, however, need to be complemented by interpretation to become meaningful (Muller 2018). In the present case, the qualitative analysis introduced in earlier items shows that despite the essential role the WHO plays in the global health governance, which can be improved, a shift towards hierarchization may not augment its positive side (Figure 1), but could yet increase substantially the number of occurrences like the Peruvian. The argument for knowledge-based coordination, providing the WHO the ability to allocate resources and inform decisions, but with no hierarchical power, rejects at the same time unilateralism and forced convergence.

This conjuncture can be also framed within the Pareto efficiency criterion. If the WHO is equipped to perform well in its role of supporting countries by delivering resources and high levels of reliable and relevant information before and during crises, all parties involved benefit. It is a Pareto improvement because it enhances global health governance without making non-state actors and developing countries worse off (Weimer and Vining 2017). New hierarchical global health governance, in its turn, would alter the existing distribution of costs and benefits, in the best case increasing total welfare, but potentially hitting non-state initiatives and producing losses to developing countries. In this scheme, powerful developed states would likely be in the winner group, while developing countries should naturally be clustered among the losers, which cannot be considered a Pareto improvement - one could say that this is how rich countries find a way to protect themselves against the diseases that come from poor and/or 'exotic' parts of the world.

\section{CONCLUSION}

There are great political stakes in asserting and, if the case, defining the equilibrium between domestic and international orders, a question that comes to light and seems particularly relevant in the face of a global disease outbreak, but that extends far beyond the health area. The optimal point of international integration raises 
questions in topics like sovereignty, global security, socioeconomic inequality across countries, and the right and duty to humanitarian intervention, just to mention a few. Striking a balance between respecting the countries self-determination but, at the same time, protecting the interests of the international community is a continuing challenge.

The debate galvanized by the spread of the novel coronavirus is representative of this scenario. Many well-intentioned scholars have proposed a more neat and hierarchical global health governance, establishing the WHO as a de jure and de facto director of the system. Even though some of the formulations are somewhat cryptic, by reading between the lines it is possible to assert that the intention is to create an architecture able to bend national states when necessary. This article raises four key points that may (or should) prevent this change to happen.

First, the system would be propitious to the imposition of universal policies (one-size-fits-all), with results on the ground that are historically irregular, to say the least. Second, powerful governments politicize multilateral institutions, many of which are vulnerable to political influence. There is no reason to believe that the WHO will be different. Therefore, the intended centralization tends to not be a Pareto improvement, because it will create winners and losers, with developing countries at risk of paying the price of the reform. Third, a more centralized model of global health governance may crowd out important initiatives that today are accomplished by non-state actors. And fourth, the hierarchization of the system may disregard democracies and the fact that, to some extent, the WHO is unidimensional, while governments are multidimensional they need to decide based not only on immediate health concerns, but considering a myriad of factors, both in the short and long run. One of the duties of government in a globalized world is to be a cushion between its people and global policies that may not be of interest or appropriate to the country's specificities.

This broad criticism does not mean that there are no good arguments for the impetus to change the existing model - the academic concerns are legitimate and the current system does provide fodder for controversies. In sum, the concerns and the call for reform are correct. The solution proposed is deemed to be wrong. Following PisaniFerry's (2018) advice, countries should not invest their hopes in audacious schemes of cooperation that may be inefficient. The way forward is to design a sufficient multilateral basis for flexible arrangements and to equip policymakers with a toolkit for decisionmaking on a field-by-field basis. In this sense, as a knowledge and resources provider, the WHO can work in close consultation with national authorities, not as superior, helping them to identify the main problems the country faces and what could be the best solutions. If the point is to improve the WHO's operational capacity and its ability to issue technical guidance and coordinate with countries, then there is still room for strengthening the organization's mandate. But knowledge must drive its role, not hierarchical power. 


\section{REFERENCES}

1. Andreoni J \& Payne AA. 2003. Do Government Grants to Private Charities Crowd Out Giving or Fund-raising? American Economic Review, 93(3): 792-812. DOI: 10.1257/000282803322157098.

2. Bauer S. 2007. Darren G. Hawkins, David A. Lake, Daniel L. Nielson, and Michael J. Tierney (Eds.): Delegation and Agency in International Organizations: (Cambridge University Press, 2006)," The Review of International Organizations 2, no. 3 (August 21, 2007): 305-7, https://doi.org/10.1007/s11558-007-9025-y.

3. Boettke P. 2021. The Struggle for a Better World. Mercatus Center, Washington.

4. Chorev N. 2012. The World Health Organization between North and South. Cornell University Press, Ithaca.

5. Cockerham WC, Hamby BW \& Oates GR. 2017. The Social Determinants of Chronic Disease. Am J Prev Med 52, no. $1 \mathrm{~S} 1$. https://dx.doi.org/10.1016\%2Fj.amepre.2016.09.010.

6. Cohen J. 2006. The New World of Global Health. Science, 311, no. 5758, 162-167. DOI: $10.1126 /$ science.311.5758.162.

7. Dieleman JL. 2006. Development assistance for health: past trends, associations, and the future of international financial flows for health. Lancet 387(10037): 25362544. DOI: 10.1126/science.311.5758.162.

8. Fazal T. 2020. "Health Diplomacy in Pandemical Times," International Organization 74(S1): E78-E97. doi:10.1017/S0020818320000326.

9. Feldstein M. 1998. Refocusing the IMF. Foreign Affairs 77(2). Accessed on 20 April 2021. https://www.foreignaffairs.com/articles/asia/1998-03-01/refocusing-imf.

10. Ferigato $S$ et al. 2020. The Brazilian Government's mistakes in responding to the COVID-19 pandemic, The Lancet 396 (10263): 1636.https://doi.org/10.1016/S0140-6736(20)32164-4.

11. Fidler DP. 2007. Architecture amidst Anarchy: Global Health's Quest for Governance. Indiana University, Articles by Maurer Faculty 329. https://www.repository.law.indiana.edu/facpub/329.

12. Fothergill A \& Peek LA. 2004. Poverty and Disasters in the United States: A Review of Recent Sociological Findings. Natural Hazards 32. https://doi.org/10.1023/B:NHAZ.0000026792.76181.d9.

13. Frenk J. and Moon S. 2013. Governance Challenges in Global Health. New England Journal of Medicine 368: 936-942. DOI: 10.1056/NEJMra1109339.

14. Gelfand MJ, Harrington JR, \& Jackson JC. 2017. The Strength of Social Norms Across Human Groups. Perspect PsycholSci 12(5). Doi: 10.1177/1745691617708631.

15. Gostin LO et al. 2020a. Reimagining Public Health section. AJPH 110 (11), 16051623. https://doi.org/10.2105/AJPH.2020.305861. 
16. Gostin LO et. al. 2020b. US withdrawal from WHO is unlawful and threatens global and US health and security," The Lancet, Comment 396(10247): 293-295. doi: 10.1016/S0140-6736(20)31527-0.

17. Haerpfer $C$ et al. 2020. World Values Survey: Round Seven. JD Systems Institute \&WVSA Secretariat, Madrid, Spain \& Vienna, Austria. doi.org/10.14281/18241.1.

18. Hale T et al., "Coronavirus Government Response Tracker", University of Oxford, January 7, 2021. https://www.bsg.ox.ac.uk/research/researchprojects/coronavirus-government-response-tracker\#data.

19. Hawkley LC \& Cacioppo JT. 2010. Loneliness Matters: A Theoretical and Empirical Review of Consequences and Mechanisms. Annals of Behavioral Medicine 40(2). doi: 10.1007/s12160-010-9210-8.

20. Kingdon J. 2011. Agendas, Alternatives, and Public Policies. Longman, New York.

21. Leng A \&Lemahieu H. 2021. Covid Performance Index: deconstructing pandemic responses. Lowi Institute, Access on 13 March 2021. https://interactives.lowyinstitute.org/features/covid-performance/.

22. McLaughlin M. 2020. Coronavirus in Scotland: We must learn from Sweden's light-touch approach, Sturgeon adviser says, The Times, September 28, 2020. https://www.thetimes.co.uk/article/coronavirus-in-scotland-we-must-learn-fromswedens-light-touch-approach-sturgeon-adviser-says-fft2f6dm6.

23. Mehtar S et al. 2020. Limiting the spread of COVID-19 in Africa: one size mitigation strategies do not fit all countries. Global Health 8, no. 7. https://doi.org/10.1016/S2214-109X(20)30212-6.

24. Moon S et al. 2017. Post-Ebola reforms: ample analysis, inadequate action. BMß56:j280. doi: 10.1136/bmj.j280.

25. Moon S. Forthcoming. The Past, Present, and Future of Global Health Governance. In Barnett, Pevehouse, and Raustiala.

26. Muller JZ. 2018. The Tyranny of Metrics. Princeton University Press, Princeton.

27. Nordhaus L. 2005. Paul Samuelson and Global Public Goods. Yale University. http://www.econ.yale.edu/ nordhaus/homepage/homepage/PASandGPG.pdf.

28. Patrick S. (2014). The Unruled World: The Case for Good Enough Global Governance," Foreign Affairs 93(1): 58-73. https://www.foreignaffairs.com/articles/2013-12-06/unruled-world.

29. Paul E, Brown GW, \&Ridde V. 2020. COVID-19: time for a paradigm shift in the nexus between local, national, and global health, $B M J$ Global Health, 5:e002622. doi:10.1136/bmjgh-2020-002622.

30. Petherick $A$ et al. 2020. Do Brazil's COVID-19 government response measures meet the WHO's criteria for policy easing?" BSG Working Paper Series, University of Oxford. https://www.bsg.ox.ac.uk/research/publications/do-brazils-covid-19government-response-measures-meet-whos-criteria-policy. 
31. Pierce $M$ et al. 2020. Mental health before and during the COVID-19 pandemic: a longitudinal probability sample survey of the UK population, Lancet Psychiatry 7. https://doi.org/10.1016/S2215-0366(20)30308-4.

32. Pisani-Ferry J. 2018. Should We Give up on Global Governance? Bruege/ 17. https://bruegel.org/wp-content/uploads/2018/10/PC-17-2018.pdf.

33. Raustiala K. 2016. Governing the Internet, The American Journal of International Law 110, (3): 491-503. http://www.jstor.org/stable/10.5305/amerjintelaw.110.3.0491.

34. Ravallion M. 2016. The World Bank: Why It Is Still Needed and Why It Still Disappoints," Journal of Economic Perspectives 30 (1): 77-94. DOI: 10.1257/jep.30.1.77.

35. Rocklöv J \&Sjödin H. 2020. High population densities catalyse the spread of COVID-19", Journal of Travel Medicine 27 (3). https://doi.org/10.1093/jtm/taaa038.

36. Roser M et al. 2021. Coronavirus Pandemic (COVID-19), Our World in Data, Access on March 29, 2021. https://ourworldindata.org/coronavirus.

37. Sher L. 2020. The impact of the COVID-19 pandemic on suicide rates. QJM: An International Journal of Medicine 113 (10): 707-12. https://doi.org/10.1093/qjmed/hcaa202.

38. Sjödin $\mathrm{H}$ et al. 2020. Only strict quarantine measures can curb the coronavirus disease (COVID-19) outbreak in Italy, 2020", Eurosurveillance 25 (13).https://www.eurosurveillance.org/content/10.2807/15607917.ES.2020.25.13.2000280.

39. Sridhar D \& Woods N. 2013. Trojan Multilateralism: Global Cooperation in Health. Global Policy 4(4), Wiley Online Library: 325-335. https://doi.org/10.1111/17585899.12066.

40. Taj M and Kurmanaev A. 12 June 2020. Virus Exposes Weak Links in Peru's Success Story The New York Times. https://www.nytimes.com/2020/06/12/world/americas/coronavirus-peruinequality-corruption.html.

41. Veaux RD, Velleman PF, \& Bock DE. 2020. Stats: Data and Models Pearson, Hoboken.

42. Vicenti $M$ et al. 2020. Lockdown timing and efficacy in controlling COVID-19 using mobile phone tracking. The Lancet, EClinicalMedicine 25. https://dx.doi.org/10.1016\%2Fj.eclinm.2020.100457.

43. Wang $C$ et al. 2020. Immediate Psychological Responses and Associated Factors during the Initial Stage of the 2019 Coronavirus Disease (COVID-19) Epidemic among the General Population in China, Int. J. Environ. Res. Public Health 17 (5): 1729.doi: 10.3390/ijerph17051729. 
44. Watson K. 2020. Coronavirus: Brazil's Bolsonaro in denial and out on a limb. $B B C$ News, Access on 20 April 2021. https://www.bbc.com/news/world-latin-america52080830.

45. Weimer DL \& Vining AR. 2017. Policy Analysis: Concepts and Practice. Routledge, Taylor \& Francis Group, New York.

46. World Health Organization - WHO. 2020. Strategic preparedness and response plan. Accessed on 15 April 2021. https://www.who.int/publications/i/item/strategic-preparedness-and-responseplan-for-the-new-coronavirus.

47. World Health Organization - WHO. 2021. WHO Coronavirus (COVID-19) Dashboard. Accessed on 6 June 2021. https://covid19.who.int.

48. Yanez D. 2020. COVID-19 mortality risk for older men and women", BMC Public Health 20(1742). https://doi.org/10.1186/s12889-020-09826-8.

49. Zürn M. 2012. Globalization and Global Governance, in Handbook of International Relations, Oxford University Press, Oxford. 